\title{
Correction to: Post-traumatic stress disorder and incident fractures in the Danish population
}

\author{
T. Jiang ${ }^{1} \cdot$ K. Veres ${ }^{2}$ - D.K. Farkas ${ }^{2} \cdot$ T.L. Lash ${ }^{2,3} \cdot$ H.T. Sørensen ${ }^{2} \cdot$ J.L. Gradus ${ }^{1,2,4,5}$ \\ Published online: 15 July 2021 \\ (C) International Osteoporosis Foundation and National Osteoporosis Foundation 2021
}

Correction to: Osteoporosis International (2018) 29:2487-

2493.

https://doi.org/10.1007/s00198-018-4644-0

The original version of this article, published on 20 August 2018, unfortunately contained a mistake.

In this article the author name H. T. Sørensen was incorrectly written as H. Toft Sørensen.

The original article has been corrected.

Publisher's note Springer Nature remains neutral with regard to jurisdictional claims in published maps and institutional affiliations.

The online version of the original article can be found at https://doi.org/ 10.1007/s00198-018-4644-0

\section{J.L. Gradus}

jgradus@bu.edu

1 Department of Epidemiology, Boston University, 715 Albany Street, Boston, MA 02118, USA

2 Department of Clinical Epidemiology, Aarhus University Hospital, Aarhus, Denmark

3 Department of Epidemiology, Rollins School of Public Health, Emory University, Atlanta, GA, USA

4 Department of Psychiatry, Boston University, Boston, MA, USA

5 National Center for PTSD, VA Boston Healthcare System, Boston, MA, USA 